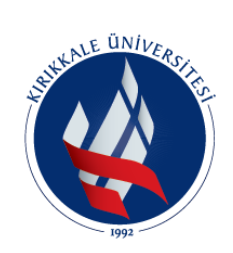

International Journal of

Engineering Research and

Development

UMAGD, (2021) 13(3), s130-s136.

Cilt/Volume:13 Sayı/Issue:3 Aralık/December 2021 Özel Sayı/ Special Issue

Seçilmiş Konferans Makalesi / Selected Conference Paper

\title{
Sürdürülebilir Üretim Çizelgeleme Problemlerinde İnsan Faktörü
}

\section{The Human Factor in Sustainable Production Scheduling Problems}

\author{
Muhammed Zahid Koç ${ }^{1}$ iD, Çağrı Sel ${ }^{1}$ iD, Fatih Keskinkılıç ${ }^{2}$ iD \\ ${ }^{1}$ Karabük Üniversitesi, Mühendislik Fakültesi Demir Çelik Kampüsü 78050 Karabük, TÜRKIYE \\ ${ }^{2}$ Kırşehir Ahi Evran Üniversitesi, Teknik Bilimler MYO Müdürlüğü, 40100 Kırşehir, TÜRKIYE
}

Başvuru/Received: 01/10/2021

Kabul/Accepted: 30/12/2021

Çevrimiçi Basım/Published Online: 31/12/2021

Son Versiyon/Final Version: 31/12/2021

\section{$\ddot{O} \mathbf{z}$}

Küresel ısınma, kuraklık ve iklim krizi gibi günlük hayatımızda daha sık duymaya başladığımız sorunların başlıca sebeplerinden biri üretim süreçleridir. Üretim sektörü enerji kaynaklarının çoğunu tüketmektedir, bununla birlikte yüksek miktarda $\mathrm{CO}^{2}$ salınımı ile çevreye zarar vermektedir. Üretim sektörü artan nüfus, kısıtlı hammadde ve kaynaklar sebebiyle rekabete dayalıdır. Üretimin çevreci ve sosyal sürdürülebilir hedeflere odaklanması, bu hedefler ek maliyetler getiriyorsa zordur. Ancak planlama ve çizelgeleme gibi üretim yönetim süreçlerinde bu hedefler gözetilerek daha az emek ve maliyetle üretim planlandığında kaynaklardan ve enerjiden tasarruf edilerek eş zamanlı olarak sürdürülebilir verimlilik hedefine ulaşılmaktadır. Bir üretimi planlarken onu sürdürülebilir kılmanın hızlı ve etkin yollarından biri de üretim çizelgesini yeniden tasarlamaktır. Sürdürülebilir çizelgeleme problemlerinde, insan faktörü göz önüne alındığında bütün sosyal paydaşlar açısından sürdürülebilir bir üretim ortamı sağlanacaktır. Bu çalışmada üretimde sürdürülebilir makine çizelgeleme problemleri incelenerek bir literatür araştırması yapılmıştır. Sürdürülebilir üretim çizelgeleme problemlerinde insan faktörü üzerine yapılan araştırmalara yönelik artan ihtiyacı ortaya koyan bir mevcut durum analizi yapılmıştır ve potansiyel çalışma alanları tartışılmıştır.

\section{Anahtar Kelimeler}

Sürdürülebilir üretim yöntemleri, makine çizelgeleme, insan faktörü, sevk kurallarl, sosyal sürdürülebilirlik

\begin{abstract}
The manufacturing processes are one of the main causes of the problems that we encounter frequently in our daily lives, such as global warming, drought, and climate crisis. The manufacturing sector depletes the energy resources and harms the environment with high $\mathrm{CO}^{2}$ emissions. The manufacturing sector is competitive due to the increasing population, the limited raw materials, and the resources. The manufacturing sector can focus on environmental and social sustainability goals under additional costs. In production management processes such as planning and scheduling, when production is planned with less labour and cost by considering the goal of sustainable efficiency is achieved simultaneously by saving resources and energy. One of the quick and efficient way to plan the sustainable production is to redesign the production scheduling. Considering the human factor in sustainable scheduling problems enable all stakeholders to have a sustainable production environment. In this study, literature research has conducted on sustainable production scheduling problems. The current literature is examined to reveal that considering the human factor is a need for sustainable production scheduling problems, and the potential future directions are discussed.
\end{abstract}

\section{KeyWords}

Sustainable production methods, machine scheduling, human factor, dispatching rules, social sustainability 


\section{Giriş}

Sürdürülebilirlik günümüzün en çok ilgi duyulan konularındandır. Üretim sektörünün ciddi miktarlarda sera gazı salınımı, enerji ve hammadde tüketimi söz konusudur. Sürdürülebilir üretim yöntemleri artık üreticiler için kaçınılmaz birer zorunluk haline gelmiştir. Sürdürülebilir verimlilik hedefine modern üretim yönetimi yaklaşımları ile ulaşılmaktadır. Bir üretim tesisinde sürdürülebilirlik hedefini makine parkurunu yenileyerek, ürün üzerinde çalışarak veya üretim yönetimini yeniden tasarlayarak gerçekleştirebiliriz. Sürdürülebilir üretimi ürün ve makine seviyesinde gerçekleştirmek istediğimizde ciddi ilk yatırım maliyetleri ve zaman gerekmektedir. Ancak üretim yönetimi açısından ele aldığımızda ek bir maliyet veya iş oluşturmadan üretimi sürdürülebilir kılmak mümkündür. (Peng vd., 2018). Geri dönüşüm, tekrar kullanım, çevresel zararları azaltma, sürdürülebilir üretim için yapılması gereken yatırımlar yerine etkin ve bu hedefleri gözeten bir çizelgeleme yöntemi geliştirilebilir.

Çizelgeleme problemleri uzun zamandır çokça çalışılmış olmasına rağmen gerçek dünyayı temsil eden, gerçek verilerle test edilen veya dinamik yapılı çalışmaların az sayıda olduğu bilinmektedir. Üretim ortamında birçok amacı aynı anda optimize etmek gerekmektedir. Ancak 1950'lerden beri çizelgeleme problemleri tek amaçlı optimizasyon problemleri şeklinde çalışıla gelmiştir. Ayrıca üretim ortamının dinamik yapısı göz ardı edilerek çoğunlukla statik problemler çalışılmışıtır. Literatürdeki çizelgeleme problemlerinin matematiksel varsayımlara dayandığı ve birbirleriyle çelişen hedefleri göz ardı ederek yalnızca bir amacı (çoğunlukla atölye tamamlanma süresini) ele alarak çözüm yöntemleri geliştirildiği bilinmektedir. Bununla birlikte araştırmacılar, son zamanlarda tek taraflı ekonomik hedeflere odaklanmak yerine gelişen çevresel ve sosyal kaygıları da göz önüne alan konular (örneğin, enerji verimli ve sosyal adaleti sağlayan üretim sistemleri) üzerine yoğunlaşmaktadır. Bu durum birbirleriyle çelişebilen iki veya daha fazla hedefi aynı anda değerlendirmeyi kaçınılmaz hale getirmiştir.

Sürdürülebilir üretim, olumsuz çevresel etkileri en aza indiren, enerji ve doğal kaynakları koruyan, çalışanlar, topluluklar ve tüketiciler için güvenli ve ekonomik olarak sağlam süreçleri kullanan üretilmiş ürünlerin oluşturulması şeklinde tanımlanmaktadır (https://www.oecd.org/sti/41503582.pdf). Sürdürülebilirlik gelecek nesillerin kendi ihtiyaçlarını karşılama yeteneğinden ödün vermeden şimdiki nesillerin ihtiyaçlarını karşılama şeklinde de ifade edilmektedir. Tablo 1'de sürdürülebilir üretimin tetikleyici unsurlarından bahsedilmektedir. Bu çalışma üretim çizelgeleme problemlerinde sürdürülebilirlik hedeflerinin literatürde nasıl ele alındığını ortaya koyarak, özellikle insan faktörünün bundan sonraki çalışmalarda dikkate alınması ile, üretim ortamlarının sosyal sürdürülebilirliğinin artırılması hedeflenmektedir.

Tablo 1. Sürdürülebilir üretimin tetikleyici unsurları

\begin{tabular}{l}
\hline Sürdürülebilir üretim neden gereklidir? \\
\hline Çevresel kaygılar \\
Yenilenemeyen kaynakların azalması \\
Daha katı mevzuat \\
Sürdürülebilir üretim teşvikleri, hibe destekleri \\
Yüksek enerji maliyetleri \\
Çevre dostu ürünler (üretim) için artan tüketici tercihi \\
\hline
\end{tabular}

$\mathrm{Bu}$ çalışmanın giriş bölümünü takip eden ikinci bölümde literatür taraması bölümüne yer verilmiştir. Literatür taramasında sürdürülebilir üretim göstergelerinin neler olduğu tanımlanmış ve literatürdeki sürdürülebilir üretim çizelgeleme problemleri bu göstergeler açısından incelenmiştir. Üçüncü ve son bölümde literatür bilgilerinden elde edilen sonuçlar değerlendirilmiştir ve potansiyel çalışma alanları tartışılmıştır.

\section{Literatür Taraması}

2010 yılından itibaren Web of Science veri tabanında, SCI-Expanded ve SSCI dergilerde yer alan makaleler incelenmiştir. Sürdürülebilirlik ile ilgili hedeflere vurgu yapmayan ve matematiksel programlama modeli yöntemi içermeyen makaleler araştırmaya dahil edilmemiştir. Seçilen makalelerden 126 makaleden yalnızca insan faktörünü dikkate alan 6 adet araştırmanın olduğu gözlenmiş ve az sayıdaki bu araştırmalar ele aldığı sürdürülebilirlik göstergeleri açısından detaylandırılmıştır.

İlk olarak 2007 yılında Mouzon vd. tarafından çalışılan sürdürülebilir üretim çizelgeleme problemlerine ilgi son yıllarda giderek artmıştır. İlgili çalışmaların atıf sayılarının da hızla artması konunun önemini ortaya koymaktadır (Şekil 1). 


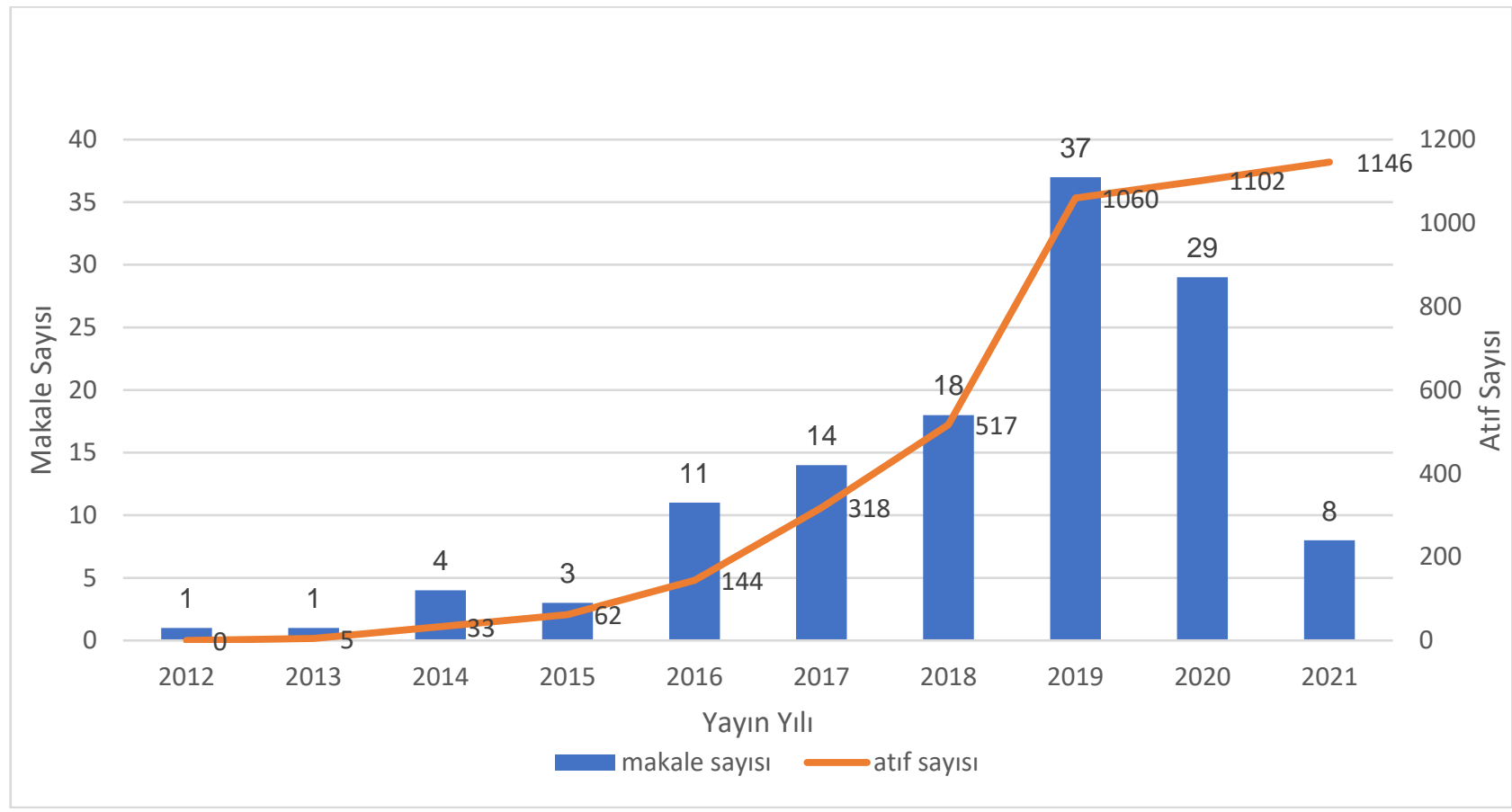

*2021 yılına ait araştırmalar halen devam etmektedir.

Şekil 1. 2010-2021 yılları arasında literatürde yer alan sürdürülebilir üretim çizelgeleme problemleri

\subsection{Sürdürülebilir Üretim Göstergeleri}

Sürdürülebilir üretim göstergeleri, ekonomik, çevresel ve sosyal olmak üzere üç alt başlıkta değerlendirilmektedir. Çizelgeleme literatüründe, öteden beri çalışılan ekonomik göstergelerin yanında, son yıllarda çevresel göstergeler de yer almaya başlamıştır. Ancak sosyal göstergeler yeterince ilgi alanı oluşturmamıştır. Günümüzde birçok çevresel ve ekonomik göstergenin aynı amacı optimize edebildiği görülmektedir. Örneğin, toplam enerji kullanımını minimize etmek çevresel bir gösterge olsa da sonucunda enerji maliyetini azalttığı için aynı zamanda ekonomik bir göstergedir. En az bu hedefler kadar önemli bir başka konu da sosyal sürdürülebilirliktir. Sosyal kaygıların çizelgeleme problemlerinde ele alınması ve üreticilerin en önemli beşerî sermaye kaynağı olan personellerinin sürdürülebilir bir çalışma ortamında verimli çalışmaları sağlanmalıdır. Sosyal hedefler gözetildiğinde personel sirkülasyonunun azaldığı, işletme hafızasının arttı̆̆ı, üretim hataların azaldığı, iş kazası risklerinin azaldığı, personel ve müşteri memnuniyetinin sağlandığı, kaliteli ve verimli bir üretim ortamı mümkündür.

Çalışan sirkülasyonu arttıkça süreç verimliliği düşmektedir. Çalışanların elde tutulması, devamsızlığın (işe devam etmeme) azaltılması, ücret ve yan haklar gibi sosyal göstergelerin iyileştirilmesi şirketin toplum nezdinde imajını ve itibarını iyileştirmeye ve üretkenliği artırmaya olanak sağlamaktadır (Laureani ve Antony, 2010; Mendiola vd., 2013)

Sosyal sürdürülebilirlik göstergelerinden bazıları, toplumdaki işgücü mevcudiyeti, işyerinin yaşam kalitesi, işyerinin güvenliliği, maaş ve diğer haklar olarak belirtilmektedir (Helleno vd., 2017). Böylece sosyal göstergeler başlı̆̆ altında ekonomi, memnuniyet seviyesi, kalite ve sağlık, insan kaynakları ve topluluk alt başlıkları altında toplayabiliriz. Bu başlıklara ek olarak, çalışan memnuniyeti, işe devam durumu, çalışan sirkülasyonu, sağlık programları ve çalışan güvenliği, ergonomi, gürültü düzeyi, işyerinin konumu (işçinin işyerine erişimi), vasıflı işçilik, işe alım-seçim, eğitim saatleri, çalışanların performansları, halk sağlı̆̆ı, topluluk geliştirme gibi göstergeler belirlenebilir. Ayrıca iş kazası ve meslek hastalığı oranı, çalışan katılımı, işçi-işveren ilişkisi, çalışanın refahı, çalışanın eşitliği (cinsiyet eşitliği), işyeri sağlığı ve güvenliği, işgücü verimliliği de bu göstergelere eklenebilir.

Tablo 2'de, sürdürülebilir üretim göstergeleri verilmiştir. Literatürde sosyal sürdürülebilirlik başlı̆ğ altında şu ana kadar sadece gürültü düzeyi ile ilgili çalışmalar mevcuttur. Birçok sürdürülebilirlik göstergesinin üretim çizelgeleme problemleri literatüründe henüz çalışılmadığı görülmektedir.

Tablo 2. Sürdürülebilir Üretim Göstergeleri (Akbar ve Irohara, 2018; Amrina ve Vilsi, 2015; Helleno vd., 2017). 


\begin{tabular}{|c|c|c|}
\hline Ekonomik & Sosyal & Çevresel \\
\hline $\begin{array}{l}\text { Finansal performans } \\
\text { - Net kar aralığı } \\
\text { - Yatırım getirisi } \\
\text { - Maliyet tasarrufu }\end{array}$ & $\begin{array}{c}\text { Topluluk } \\
\text { - Sürdürülebilirlik ödülleri } \\
\text { - Müşteri şikayetleri } \\
\text { - Müşteri }\end{array}$ & $\begin{array}{c}\text { Emisyon ve Kirleticiler } \\
\text { - Su atık deşarjı } \\
\text { - Üretilen katı atık } \\
\text { - Atık enerji emisyonu } \\
\text { - Zararlı gaz salınımı } \\
\text { - Atık ayrı̧tırma yüzdesi } \\
\text { * Sera gazı emisyonları ve karbon ayak izi }\end{array}$ \\
\hline $\begin{array}{c}\text { Üretim maliyeti } \\
\text { - Malzeme maliyeti } \\
\text { - Personel maliyeti } \\
\text { - İşletme ve sermaye maliyetleri } \\
\text { - Envanter/stok maliyeti } \\
\text { - Ürün teslimatı } \\
* \text { Enerji maliyeti }\end{array}$ & $\begin{array}{c}\text { Personel } \\
\text { - Kayıp iş günleri } \\
\text { - Çalışan yıpranması/sirkülasyon } \\
\text { - Kişisel koruyucu donanım ekipmanları } \\
\text { - Kaza oranı } \\
\text { - Personel ilişkileri } \\
\text { - Personel sürdürülebilirlik eğitimi } \\
\text { - Personel verimliliği } \\
\text { * Gürülttü düzeyi }\end{array}$ & $\begin{array}{c}\text { Kaynak Tüketimi } \\
\text { - Üretimde yeniden kullanım } \\
\text { - Ambalaj malzeme atı̆̆ } \\
\text { - Enerji yoğunluğu } \\
\text { - Ürünlerden elde edilen enerji } \\
\text { - Su yoğunluğu } \\
\text { - Suyun tekrar kullanımı } \\
\text { - Araç yakıt tüketimi } \\
\text { - Hatalı ürün yüzdesi } \\
\text { - Yeşil hammadde kullanım yüzdesi } \\
\text { * Enerji verimliliği ve elektrik güç tüketimi }\end{array}$ \\
\hline
\end{tabular}

* Tabloda vurgulanan hedefler literatürde sıklıkla çalışılan hedeflerdir.

\subsection{Sürdürülebilir Çizelgeleme Problemleri}

Üretim çizelgeleme, üretim kaynaklarının (insan, makine vb.) belirli zaman dilimlerinde görevlere tahsis edilmesi ve belirlenen amaçları optimize etmektir. Atölyenin toplam tamamlanma zamanının, atölye süresinin, toplam akış süresinin, maksimum gecikme süresinin, toplam gecikme süresinin veya geciken iş sayısının minimizasyonu makine çizelgeleme problemlerinin geleneksel hedeflerine örnek olarak verilebilir. Son yıllarda sürdürülebilirlik ile ilgili amaçlar makine çizelgeleme problemlerinde dikkate alınmaya başlasa da birçok sürdürülebilirlik göstergesi olmasına rağmen literatürde genellikle bu göstergelerden çok azının çalışıldığı görülmektedir. Literatürde en çok çalışılan hedefler toplam enerji maliyetini ve atölye tamamlanma süresini (Cmax) minimize etmektir (Şekil 2).

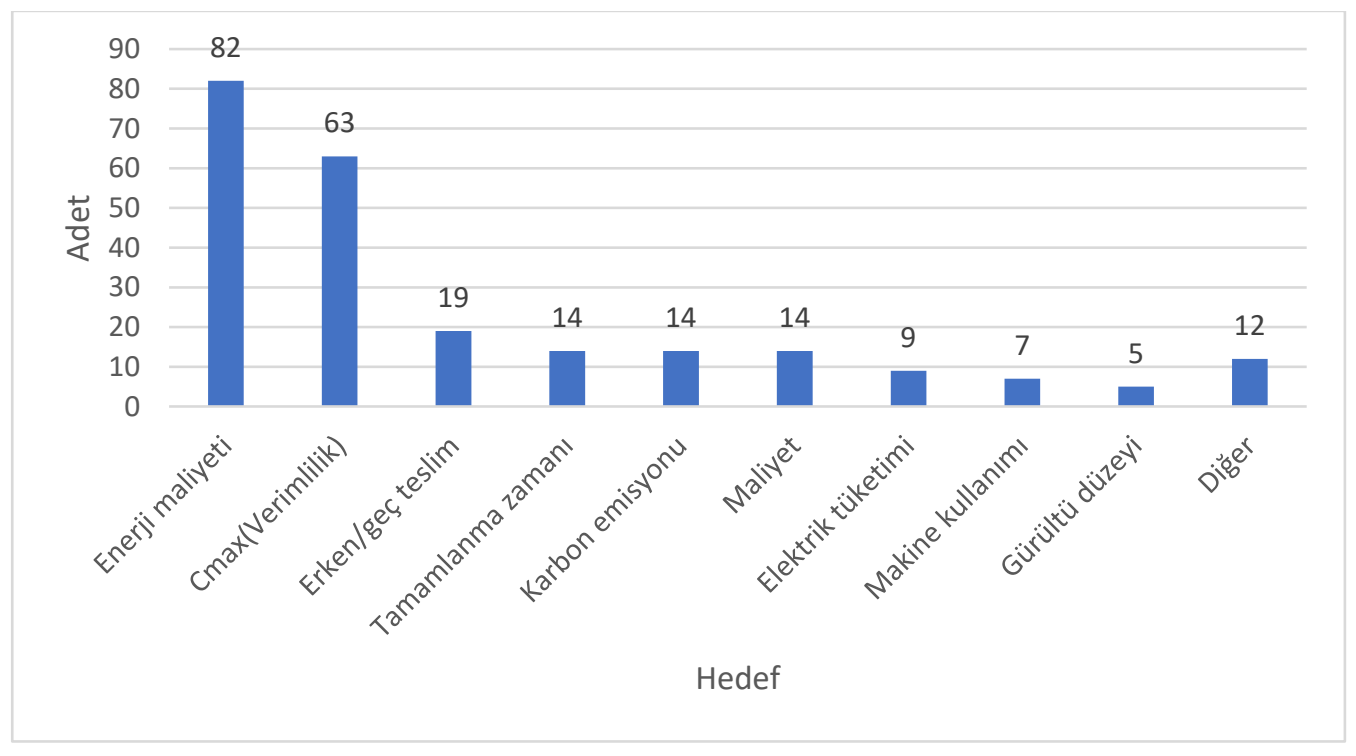

Şekil 2. Sürdürülebilir üretim çizelgeleme problemlerinin amaç fonksiyonları

Makine çizelgeleme problemlerinin notasyonu incelendiğinde üretim ortamı, dikkate alınan kısıtlar ve optimize edilecek hedefler yer almaktadır (Allahverdi vd., 2008). Örneğin, $P m|s i j| C m a x$ şeklinde bir notasyona sahip problem de, paralel makineli üretim ortamında sıra bağımlı hazırlık süreleri dikkate alınarak atölyenin maksimum tamamlanma süresinin optimize edilmeye çalışıldığı anlaşılmaktadır. Literatür incelenerek ilgili problemler bu notasyonlar yardımıyla, üretim ortamlarına göre, optimize edilmesi istenen amaç sayısına göre ve varsa sürdürülebilir hedeflere göre sınıflandırma yapılabilmektedir. Ayrıca literatürde ele alınan problemleri çözüm yöntemlerine göre de sınıflandırmak mümkündür (Tablo 3).

Tablo 3.Çizelgeleme problemlerinin sınıflandırılması 


\begin{tabular}{llll}
\hline Çözüm yöntemine göre & Üretim ortamına göre & Sürdürülebilirlik hedefine göre & Amaç sayısına göre \\
\hline Kesin yöntem & Tek makine & Toplam enerji tüketimi & Tek amaçlı \\
Sezgisel yöntem & Paralel makine & Karbon emisyonu & İki amaçlı \\
Meta-sezgisel yöntem & Akış tipi & Atık yönetimi & Çok amaçlı \\
Simülasyon & Atölye tipi & & \\
\hline
\end{tabular}

Literatürde, insan faktörünün sürdürülebilir hedefler içinde yer aldığını görülmektedir. Böylece insan faktörünü dikkate alan problemlerin geleneksel çizelgeleme hedefi yanında bir de sürdürülebilirlik hedefine de sahip olduğu çok amaçlı optimizasyon problemlerine evrildikleri görülmektedir. Dolayısıyla bu problemlerin çözümünde aynı anda birden fazla hedefi optimize etmek gerektiği görülmektedir. Literatür taraması neticesinde amaç fonksiyonunda sosyal sürdürülebilirlik göstergelerine sahip makaleler tespit edilmiştir ve gürültü düzeyi/kirliliği dışında diğer sosyal göstergelerin çalışılmadığı görülmektedir (Tablo 4). Bu problemlerin hepsinin çok amaçlı optimizasyon problemleri olduğu ve meta-sezgisel algoritmalar geliştirilerek çözüldüğü tespit edilmiştir.

Tablo 4. Literatürde yer alan sosyal sürdürülebilirlik hedefine sahip makine çizelgeleme problemleri.

\begin{tabular}{|c|c|c|c|c|c|}
\hline Yazar & Dergi & Anahtar kelimeler & Amaç Fonksiyonu & $\begin{array}{l}\text { Üretim } \\
\text { ortamı }\end{array}$ & Çözüm Yöntemi \\
\hline Yin vd. (2017a) & $\begin{array}{l}\text { Sustainable } \\
\text { Computing: } \\
\text { Informatics } \\
\text { and Systems }\end{array}$ & $\begin{array}{c}\text { Düşük karbon çizelgeleme, } \\
\text { Çok amaçlı optimizasyon, } \\
\text { Enerji verimliliği, Gürültü } \\
\text { kirliliği** }\end{array}$ & $\begin{array}{l}\text { Üretkenliği, enerji } \\
\text { verimliliğini ve gürülttü } \\
\text { azaltmayı maksimize } \\
\text { etmek }\end{array}$ & $\begin{array}{l}\text { Esnek } \\
\text { atölye } \\
\text { tipi }\end{array}$ & $\begin{array}{l}\text { Meta-sezgisel (Çok } \\
\text { amaçlı genetik } \\
\text { algoritma) }\end{array}$ \\
\hline Yin vd. (2017b) & $\begin{array}{l}\text { Advances in } \\
\text { Mechanical } \\
\text { Engineering }\end{array}$ & $\begin{array}{c}\text { Enerji verimli çizelgeleme, } \\
\text { Çok amaçlı optimizasyon, } \\
\text { Enerji tüketimi, Gürültü } \\
\text { kirliliği* }\end{array}$ & $\begin{array}{l}\text { Üretkenliği, enerji } \\
\text { verimliliğini ve gürültü } \\
\text { azaltmayı maksimize } \\
\text { etmek }\end{array}$ & $\begin{array}{l}\text { Atölye } \\
\text { tipi }\end{array}$ & $\begin{array}{l}\text { Meta-sezgisel (Çok } \\
\text { amaçlı genetik } \\
\text { algoritma) }\end{array}$ \\
\hline C. Lu vd. (2018) & $\begin{array}{l}\text { Journal of } \\
\text { Cleaner } \\
\text { Production }\end{array}$ & $\begin{array}{l}\text { Enerji verimliliği, Çok } \\
\text { amaçlı optimizasyon, } \\
\text { Gürültü kirliliği* }\end{array}$ & $\begin{array}{l}\text { Atölye süresini, gürültü } \\
\text { kirliliğini ve toplam } \\
\text { enerji tüketimini } \\
\text { minimize etmek }\end{array}$ & $\begin{array}{l}\text { Kaynak } \\
\text { Atölyesi }\end{array}$ & $\begin{array}{l}\text { Meta-sezgisel (Karma } \\
\text { çok amaçlı hücresel gri } \\
\text { kurt algoritması) }\end{array}$ \\
\hline C. Lu vd. (2019) & $\begin{array}{l}\text { Applied Soft } \\
\text { Computing } \\
\text { Journal }\end{array}$ & $\begin{array}{l}\text { Çok amaçlı optimizasyon, } \\
\text { Hücresel otomatlar, Enerji } \\
\text { verimliliği, Gürültü kirliliği* }\end{array}$ & $\begin{array}{l}\text { Atölye süresini, gürültü } \\
\text { kirliliğini ve toplam } \\
\text { enerji tüketimini } \\
\text { minimize etmek }\end{array}$ & $\begin{array}{l}\text { Karma } \\
\text { akış tipi }\end{array}$ & $\begin{array}{l}\text { Meta-sezgisel (Çok } \\
\text { amaçlı hücresel gri kurt } \\
\text { algoritması) }\end{array}$ \\
\hline Guo vd. (2020) & $\begin{array}{l}\text { Computers } \\
\text { and Industrial } \\
\text { Engineering }\end{array}$ & $\begin{array}{c}\text { Yeșil çizelgeleme problemi, } \\
\text { İyileştirilmiş gri kurt } \\
\text { optimizasyon algoritması, } \\
\text { Karbon emisyonu, Gürültü } \\
\text { maliyeti* }\end{array}$ & $\begin{array}{c}\text { Maksimum } \\
\text { tamamlanma zamanını, } \\
\text { karbon emisyonunu ve } \\
\text { gürültü maliyetini } \\
\text { minimize etmek } \\
\end{array}$ & Akış tipi & $\begin{array}{l}\text { Meta-sezgisel } \\
\text { (İyileştirilmiş gri kurt } \\
\text { optimizasyon } \\
\text { algoritması) } \\
\end{array}$ \\
\hline
\end{tabular}

* Araştırmalarda sosyal sürdürülebilirlik göstergesi olarak yalnızca gürültü kirliliği ve maliyeti yer almaktadır.

Makine çizelgeleme problemleri kesikli kombinatoryel optimizasyon problemleri sınıfında yer almaktadır. Problemlerin NP-hard sınıfında olduğu ispatlanmıştır (Paolucci vd., 2017). Problemler, matematiksel programlama gibi kesin çözümler ile ve simülasyon yöntemleriyle modellenmiştir. Bir çözüm yaklaşımı olarak sıklıkla sezgisel ve meta-sezgisel yöntemlerin tercih edildiği görülmektedir.

Arama tabanlı sezgisel algoritmaların (tabu araması, tavlama benzetimi, genetik algoritmalar vb.) yanında ayrıca matematiksel tabanlı sezgisel sevk kuralları geliştirilmiştir. Bu kurallar üretim ortamına, üretim sektörüne, ürün yönetimine, üretici firmanın/müş̧erinin önceliklerine göre geliş̧irilmektedir. Çizelgeleme literatüründe en çok kullanılan sezgisel tabanlı sevk kuralları şunlardır; ilk giren ilk çıkar kuralı, En kısa işlem süresi kuralı, En uzun işlem süresi kuralı, En erken teslim süresi kuralı, Kritik oran kuralı, Ağırlıklı en kısa işlem süresi kuralı, En kısa hazırlık süresi kuralı. Bu kurallar incelendiğinde sürdürülebilirlik hedefini göz önünde bulundurmadıkları görülmektedir. Ayrıca üretimde insan faktörünü göz önüne alan sevk kuralları da mevcut değildir. Örneğin üretim sırasında harcanan enerji miktarını minimize edecek şekilde bir çizelgeleme geliştirilmemiştir. Üretim ortamına bağlı olarak harcanan kimyasal madde miktarını, harcanan su miktarını, ortaya çıkan atık miktarını dikkate alan sevk kurallarının olmadığı görülmektedir. 


\section{Tartışma ve Sonuç}

Çizelgeleme literatüründe sürdürülebilir üretim problemleri 2010 yılından itibaren çalışılmaya başlamıştır. Özellikle son 5 yılda çalışmaların sayısı ciddi oranda artmıştır. Sürdürülebilir üretim göstergeleri ele alındığında birçok göstergenin literatürde yeterince temsil edilmemiş potansiyel çalışma alanları olduğu görülmektedir. Çizelgeleme literatüründe sürdürülebilir üretim enerji verimliliğine ve karbon emisyonuna indirgenmiş durumdadır (Şekil 4).

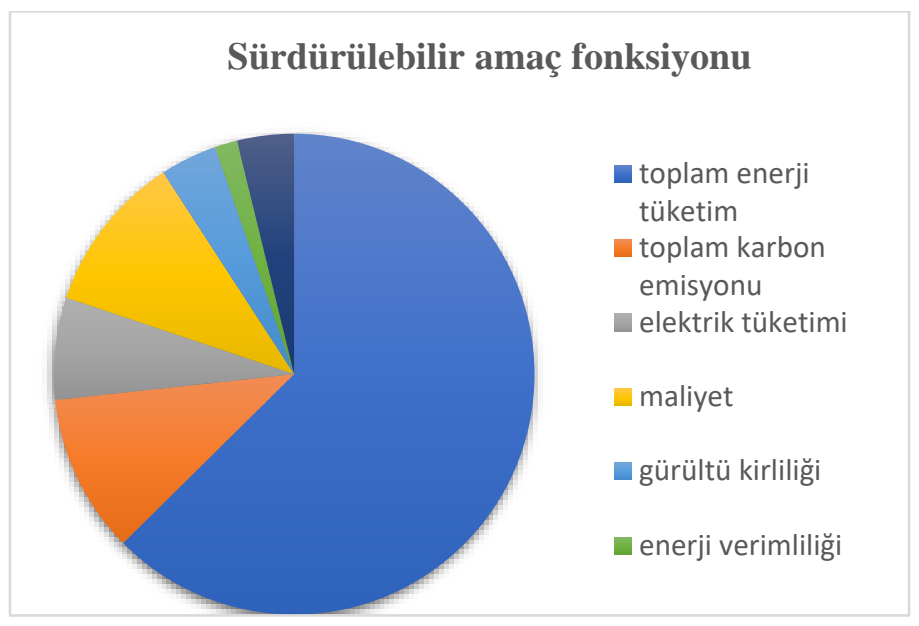

Şekil 4. Literatürde yer alan makine çizelgeleme problemlerinde sürdürülebilir amaç fonksiyonları

Bir üretim ortamını sürdürülebilir hale nasıl getiririz sorusuna cevap ararken, dikkate alınması gereken hususlardan birisi de üretimi doğrudan etkileyen insan faktörüdür. Ancak literatür incelendiğinde son yıllarda giderek artan bir şekilde literatürde yer edinmiş birçok konu çalışılmışken insan faktörünün göz ardı edildiği, nadiren bir hedef olarak problemlerde yer aldığı görülmektedir. Aslında sürdürülebilirliğin sosyal göstergeleri altında değerlendirilen insan faktörünün matematiksel bir problem halinde ele alınmasının zorluğu da bu durumda önemli bir etkendir. İnsan faktörünün üretim ortamında işlem süresinin belirsizliği, işlerin zamanında teslimi, üretimin kalitesi gibi konular üzerinde önemli etkisi vardır. İnsan faktörü, henüz sürdürülebilir çizelgeleme problemleri literatüründe dikkate alınmamıştır. Sadece sosyal göstergelerden gürültü düzeyinin çalışıldığı gözlenmiştir.

Sosyal sürdürülebilirlik ile ekonomik sürdürülebilirliğin arasında sıkı ilişki olduğu önceki çalışmalarda ortaya koyulmuştur (Sudusinghe ve Seuring, 2020). Bu noktadan hareketle sürdürülebilir üretim için sosyal göstergelerinde göz önünde bulundurulması üreticileri, sosyal adaleti sağlayan bir üretim hedefine ulaştıracaktır. Bu alandaki çalışmaların gelecekte aşağıda belirtildiği çerçevede gelişerek devam edeceği değerlendirilmektedir.

- Literatürde sürdürülebilir çizelgeleme problemleri, enerji verimliliği üzerinde yoğunlaşmıştır. Gelecek çalışmalarda diğer sürdürülebilirlik göstergelerinin de (su, atık vb..) dikkate alınması gerekmektedir.

- Enerji etkin çizelgeleme problemleri incelendiğinde makineleri enerjinin ucuz olduğu saatlerde çalıştırarak, üretimi gerçekleştirme yaklaşımını görmekteyiz. Böylece enerji maliyetlerinde tasarruf sağlanabilir. Ayrıca sera gazı emisyonu azaltılabilir. Ancak bu zaman dilimi işçi/personel verimliliğinin ve personel maliyetinin dikkate alınmadığı görülmektedir. Tıpkı makineler gibi insanlarda enerji harcamaktadır. Sürdürülebilir optimizasyon problemlerinde personel yorgunluğunun da veya verimliliğinin de dikkate alınması gerekmektedir.

- Literatürdeki bir başka yaklaşım da makine hızının değiştirilerek enerji tüketiminin kontrol altına alınmaya çalışılmasıdır. Burada insan (iş̧̧i, operatör) faktörünün bir etken olarak değerlendirilmediği görülmektedir. Ancak makinenin devrini artırdığımızda hata sayısı, operatör müdahale sayısı artabileceğinden bu durumun, üretim verimliliği ve ürün kalitesi üzerindeki etkileri göz ardı edilmemelidir.

- Gürültü düzeyi dışındaki diğer sosyal sürdürülebilirlik göstergelerinin (personel sirkülasyonu, iş kazaları ve meslek hastalığı oranları gibi) personel ve üretim ortamının verimliliği üzerine etkisi, daha önce irdelenmemiş potansiyel çalışma alanları olarak değerlendirilmektedir.

- Üretim sektörünü incelediğimizde sevk kurallarının endüstriyel uygulamalarda daha yaygın kullanıldığı görülmektedir. Literatür taraması sonucu sürdürülebilir çizelgeleme problemlerinin çözümünde sevk kurallarının neredeyse hiç kullanılmadığı belirlenmiştir ve potansiyel bir çalışma alanı olduğu öngörülmektedir.

- Sürdürülebilir çizelgeleme problemlerinde geleneksel hedefe ek olarak, sürdürülebilirlik hedefi de olduğu için, çok amaçlı optimizasyon problemleri şeklinde karşımıza çıkmaktadır. Bu durumun bir sonucu olarak, gelecek çalışmalarda şimdiye kadar çoğunlukla tek amaçlı olarak ele alınan geleneksel çizelgeleme problemlerinin, gelecek çalışmalarda çok amaçlı çizelgeleme problemleri halinde ele alınacağı düşünülmektedir.

- Sürdürülebilir üretim çizelgeleme problemlerinin çözümünde sürdürülebilir sevk kuralları geliştirilerek, üretim sırasında tüketilen enerji, su, kimyasal madde miktarı gibi kaynakları minimize edecek şekilde üretim planlanabilir. 
- İnsan faktörünü göz önüne alan sevk kuralları geliştirilebilir. Böylece sosyal sevk kuralları geliştirilerek daha insan ve çevre odaklı, adil bir üretim anlayışı firmalara yerleştirilebilir.

\section{Referanslar}

Allahverdi, A., Ng, C. T., Cheng, T. E., \& Kovalyov, M. Y. (2008). A survey of scheduling problems with setup times or costs. European journal of operational research, 187(3), 985-1032. https://doi.org/10.1016/j.ejor.2006.06.060

Akbar, M., \& Irohara, T. (2018). Scheduling for sustainable manufacturing: A review. Journal of cleaner production, 205, 866-883. https://doi.org/10.1016/j.jclepro.2018.09.100

Amrina, E., \& Vilsi, A. L. (2015). Key performance indicators for sustainable manufacturing evaluation in cement industry. Procedia CIRP, 26, 19-23. https://doi.org/10.1016/j.jclepro.2016.12.072

Helleno, A. L., de Moraes, A. J. I., \& Simon, A. T. (2017). Integrating sustainability indicators and Lean Manufacturing to assess manufacturing processes: Application case studies in Brazilian industry. Journal of cleaner production, 153, 405-416. https://doi.org/10.1016/j.jclepro.2016.12.072

Laureani, A., \& Antony, J. (2010). Reducing employees' turnover in transactional services: a Lean Six Sigma case study. International Journal of Productivity and Performance Management 59(7), 688-700 https://doi.org/10.1108/17410401011075666

Mendiola, I. S., Beltran, A.G., \& Tirados, R.M.G., (2013). Evaluation and implementation of social responsibility. The Service Industries Journal, 33(9-10), 846-858. https://doi.org/10.1080/02642069.2013.719890

Mouzon G., Yildirim M.B., \& Twomey J. (2007). Operational methods for minimization of energy consumption of manufacturing equipment. International Journal of Production Research 45 (18-19) 4247-4271 https://doi.org/10.1016/j.jclepro.2016.12.072

Paolucci, M., Anghinolfi, D. \& Tonelli, F. (2017). Facing energy-aware scheduling: a multi-objective extension of a scheduling support system for improving energy efficiency in a moulding industry. Soft Computing 21(13), 3687-3698 https://doi.org/10.1016/j.jclepro.2016.12.072

Peng C., Peng T., Zhang Y., Tang R., \& Hu L. (2018). Minimising Non-Processing Energy Consumption and Tardiness Fines in a Mixed-Flow Shop. Energies. 11(12):3382. https://doi.org/10.1016/j.jclepro.2016.12.072

Sudusinghe JI., \& Seuring S. (2020). Social Sustainability Empowering the Economic Sustainability in the Global Apparel Supply Chain. Sustainability, 12(7):2595. https://doi.org/10.3390/su12072595

US Department of Commerce. Sustainable manufacturing initiative. Proceedings of the 2nd Annual Sustainable Manufacturing Summit 2009. https://doi.org/10.1016/j.jclepro.2016.12.072 